\title{
Autosomal dominant cortical tremor, myoclonus, and epilepsy: is the origin in the cerebellum? Editorial
}

\author{
Pasquale Striano • Elan D. Louis • Mario Manto
}

Published online: 5 October 2012

(C) Springer Science+Business Media New York 2012

In 1990, Ikeda et al. described an action and postural tremor that originated from the cerebral cortex and was thus termed "cortical tremor." Due to its peculiar electrophysiological features, this involuntary movement was considered to be a variant of cortical reflex myoclonus [1]. Cortical tremor was then recognized to occur in Japanese families often in association with tonicclonic seizures, and this observation led to the definition of an autosomal dominant trait named Benign Adult Familial Myoclonic Epilepsy (BAFME), which was mapped on chromosome $8 \mathrm{q}[2,3]$. Over the past decade, several European kindreds with overlapping clinical features have been reported under different acronyms, such as autosomal dominant cortical myoclonus and epilepsy and familial cortical myoclonic tremor with epilepsy (FCMTE) [4-7]. The available literature now suggests a worldwide distribution (more than 60 families have been reported) and genetic heterogeneity, yet with evidence that 2p11.1-q12.2 is a major locus for

\section{P. Striano $(\bowtie)$}

Pediatric Neurology and Muscular Diseases Unit, Department of Neurosciences, Rehabilitation, Ophthalmology, Genetics, Maternal and Child Health, University of Genoa, "G. Gaslini" Institute, Largo Gaslini 5, Pediatric Neurology and Muscular Diseases Unit, Padiglione 16, IV Piano,

16147 Genoa, Italy

e-mail: pstriano@email.it

E. D. Louis

Department of Neurology, College of Physicians and Surgeons, Columbia University,

New York, NY, USA

M. Manto

FNRS, ULB Erasme,

808 Route de Lennik,

1070 Brussels, Belgium the kindreds of European origin [8]. Most affected individuals experience tonic-clonic seizures, which begin later than "tremor." Seizures are generally rare (about five to ten episodes during life) and are not preceded by any warning. However, in some cases, they may be heralded by progressively increasing myoclonic jerks. Precipitating factors such as sleep deprivation, emotional stress, pain, and photic stimulation are often reported [3, 7]. In some cases, severe myoclonus can alter the quality of life. Although the epilepsy is usually benign, in rare cases, patients may present with drug-resistant complex partial seizures and focal EEG abnormalities [4]. Patients usually have normal cognition; however, mildto-moderate mental retardation may be present in some cases, especially in a more advanced age [6, 9]. Both the severity of seizures and the use of antiepileptic drugs could contribute to cognitive impairment. Cerebellar symptoms are usually mild: postural ataxia, downbeat nystagmus, impaired smooth pursuit. MRI may demonstrate a cerebellar atrophy. A pseudo-parkinsonism has also been reported. FCTME is usually diagnosed between the ages of 20 and 45 years. Myoclonus and EEG abnormalities progressively worsen from early to late adulthood. Clonazepam and sodium valproate are usually effective therapies.

Thus far, the pathophysiological and biochemical bases of this condition remain poorly understood. Mutations in genes encoding ion channels have been excluded by several authors [3-7]. Patients typically show giant somatosensory evoked potentials and strong cortico- and intermuscular coherence in the $8-$ to $30-\mathrm{Hz}$ range, thus suggesting an underlying cortical hyperexcitability, which can be the result of a decreased cortical inhibition by the cerebellum via its cerebello-thalamocortical projections [6]. Indeed, rare post-mortem histological studies have shown evidence of cerebellar pathology reminiscent of SCA type $6[3,5]$, and although 
there is no evident underlying structural brain abnormality at conventional MRI studies [3, 6], proton MR spectroscopy demonstrated an elevated choline/creatine ratio, suggestive of changes in the white matter-in the cerebellar cortex [10]. Notably, imaging and pathological studies suggest involvement of the cerebellum and its projection areas, even in another different and much more common condition, i.e., essential tremor (ET). In this issue of The Cerebellum, the paper by Buijink and colleagues [11] compared cerebellar fiber density in FCMTE and ET patients, and healthy controls. Their results revealed decreased mean fractional anisotropy of the cerebellum for FCMTE patients compared to controls and ET patients, whereas no difference in mean cerebellar volume was found. This study further supports the view that an abnormal cerebellar circuitry is the underlying substrate of this condition.

As the causative genes have not yet been identified, it may be only speculated that the underlying genetic defects would result in a disturbance of cortical rhythmicity and excitability, hence leading to disinhibition of the motor cortex. In fact, it is well known that the cerebellum receives information from the motor cortex and that that cerebellar output influences different neuronal populations in the motor cortex $[12,13]$. However, it remains to be elucidated whether the excessive excitability is due to the enhanced intrinsic rhythmic activity of cortical generators or to the abnormal reciprocal interactions with subcortical structures. Alternatively, decreased cortical inhibition may be caused by dysfunction of the cerebello-thalamo-cortical loop secondary to primary cerebellar pathology, especially at the level of the cerebellar cortex [14]. In addition, recent clinical studies suggest a correlation between clinical severity and patients' ages, indicating that the clinically evident progression of the disease reflects - at least in part - the effect of physiological aging [9, 15].

In conclusion, a wealth of clinical, neuroimaging, and post-mortem data indicate that this disease, or rather this family of diseases, is likely to be neurodegenerative. When causative genes are identified, it will be worthwhile testing whether their pattern of expressions is significantly altered in the cerebellum. Knowledge of the molecular mechanisms that underlie these structural changes may provide new relevant insights into its pathogenesis and for the development of targeted, effective pharmacotherapeutic interventions. Such knowledge could provide a way to elucidate the mechanisms of a relatively slow neurodegenerative process.

\section{References}

1. Ikeda A, Kakigi R, Funai N, Neshige R, Kuroda Y, Shibasaki H. Cortical tremor: a variant of cortical reflex myoclonus. Neurology. 1990;40:1561-5.

2. Mikami M, Yasuda T, Terao A, Nakamura M, Ueno S, Tanabe H, et al. Localization of a gene for benign adult familial myoclonic epilepsy to chromosome 8q23.3-q24.1. Am J Hum Genet. 1999;65:745-51.

3. Uyama MD, Fu YH, Ptacek L. Familial adult myoclonic epilepsy (FAME). In: Delgado-Escueta AV, Guerrini R, Medina MT, Genton P, Bureau M, Dravet C, editors. Advances in neurology. Vol. 95. Myoclonic epilepsies. Philadelphia: Lippincott Williams \& Wilkins; 2005. p. 281-8. Ch. 22.

4. Guerrini R, Bonanni P, Patrignani A, Brown P, Parmeggiani L, Grosse $\mathrm{P}$, et al. Autosomal dominant cortical myoclonus and epilepsy (ADCME) with complex partial and generalized seizures: a newly recognized epilepsy syndrome with linkage to chromosome 2p11.1-q12.2. Brain. 2001;124:2459-75.

5. van Rootselaar AF, Aronica E, Jansen Steur EN, RozemullerKwakkel JM, de Vos RA, Tijssen MA. Familial cortical tremor with epilepsy and cerebellar pathological findings. Mov Disord. 2004;19:213-7.

6. Striano P, Zara F, Striano S. Autosomal dominant cortical tremor, myoclonus and epilepsy: many syndromes, one phenotype. Acta Neurol Scand. 2005;111:211-7.

7. Striano P, Chifari R, Striano S, de Fusco M, Elia M, Guerrini R, et al. A new benign adult familial myoclonic epilepsy (BAFME) pedigree suggesting linkage to chromosome 2p11.1-q12.2. Epilepsia. 2004;45:190-2.

8. Madia F, Striano P, Di Bonaventura C, de Falco A, de Falco FA, Manfredi M, et al. Benign adult familial myoclonic epilepsy (BAFME): evidence of an extended founder haplotype on chromosome 2p11.1-q12.2 in five Italian families. Neurogenetics. 2008;9:139-42.

9. Coppola A, Santulli L, Del Gaudio L, Minetti C, Striano S, Zara F, et al. Natural history and long-term evolution in families with autosomal dominant cortical tremor, myoclonus, and epilepsy. Epilepsia. 2011;52:1245-50.

10. Striano P, Caranci F, Di Benedetto R, Tortora F, Zara F, Striano S. $1 \mathrm{H}$ MR spectroscopy indicates prominent cerebellar dysfunction in benign adult familial myoclonic epilepsy. Epilepsia. 2009;50:1491-7.

11. Buijink AW, Caan MW, Tijssen MA, Hoogduin JM, Maurits NM, van Rootselaar AF. Decreased cerebellar fiber density in cortical myoclonic tremor but not in essential tremor. Cerebellum. 2012 Sep 8. (In press)

12. Manto M, Bower JM, Conforto AB, Delgado-García JM, da Guarda SN, Gerwig M, et al. Consensus paper: roles of the cerebellum in motor control - the diversity of ideas on cerebellar involvement in movement. Cerebellum. 2012;11:457-87.

13. Louis ED. Essential tremor: evolving clinicopathological concepts in an era of intensive post-mortem enquiry. Lancet Neurol. 2010;9:613-22.

14. Magnin E, Labauge P, Rumbach L, Vidailhet M. Update in familial cortical myoclonic tremor with epilepsy. In: Grimaldi G, Manto M, editors. Mechanisms and emerging therapies in tremor disorders. Contemporary clinical neuroscience. New York: Springer; 2013. p. 249-62.

15. Hitomi T, Ikeda A, Kondo T, Imamura H, Inouchi M, Matsumoto $\mathrm{R}$, et al. Increased cortical hyperexcitability and exaggerated myoclonus with aging in benign adult familial myoclonus epilepsy. Mov Disord. 2011;26:1509-14. 